Original Research Article

\title{
A study of serious adverse drug reactions with antiepileptic drugs: a pharmacovigilance study
}

\author{
Shaima Zafer Khan ${ }^{1 *}$, Mohammed Abid Ali ${ }^{1}$, Ghulam Subhani ${ }^{2}$, T. Ushasree ${ }^{1}$
}

${ }^{1}$ Department of Pharmacology, Gandhi Medical College,

Telangana, India

${ }^{2}$ Department of Pharmacology,

Deccan College of Medical

Sciences, Telangana, India

Received: 19 February 2018

Accepted: 28 March 2018

\section{*Correspondence to:}

Dr. Shaima Zafer Khan,

Email: dr.shaimazafer@ gmail.com

Copyright: (C) the author(s), publisher and licensee Medip Academy. This is an openaccess article distributed under the terms of the Creative Commons Attribution NonCommercial License, which permits unrestricted noncommercial use, distribution, and reproduction in any medium, provided the original work is properly cited.

\begin{abstract}
Background: Approximately 50 million people worldwide have epilepsy, making it one of the most common neurological diseases globally. There are currently more than 25 drugs in the market for the treatment of epilepsy, many of which have similar efficacy but differ in their tolerability profile. Besides unmatched beneficial potential of antiepileptic drugs, it is associated with many adverse reactions too. This study aims to identify the serious adverse reactions caused by prescribed antiepileptics, reported at the pharmacovigilance centre of government tertiary care centre.

Methods: This is a retrospective, pharmacovigilance study of the antiepileptic drugs adverse reactions reported over a period of 1 year at a tertiary care centre. Results: A total of 120 ADRs of antiepileptic drugs were reported and collected at the pharmacovigilance centre. According to the WHO-ART system organ classification of ADRs, $78 \%$ of ADRs belonged to skin and appendages disorder. Based on the modified Hartwig and Siegel scale of severity, 60.8\% ADRs were mild, $18.5 \%$ were moderate and $20.8 \%$ were severe ADRs. The severe ADRs included: Steven-Johnson syndrome, Toxic epidermal necrolysis, Erythroderma, DRESS syndrome and Acute pancreatitis. Phenytoin has been found to be the antiepileptic drug causing the most number of severe ADRs amongst the prescribed antiepileptics. According to the modified Schumock and Thornton criteria most of the severe ADRs were not preventable.

Conclusions: This study analyses the ADRs associated with antiepileptics reported at the pharmacovigilance centre. 20.8\% ADRS were severe, this indicates that the epileptic patients should be closely monitored for ADRs, to avoid clinically significant harmful consequences. The awareness of ADRs would help physicians to identify patients with greater risk of ADRs and therefore, might benefit from ADRs monitoring and reporting programmes.
\end{abstract}

Keywords: Antiepileptic drugs, ADRs, Pharmacovigilance

\section{INTRODUCTION}

According to $\mathrm{WHO}$, approximately 50 million people worldwide have epilepsy, making it one of the most common neurological disease globally. ${ }^{1}$ About 10 million of which reside in India. $^{2}$ Epilepsy is defined by International league against epilepsy, as a condition characterised by recurrent epileptic seizures, unprovoked by any immediate identified cause. Nearly $80 \%$ of the people with epilepsy live in low- and middle-income countries and adverse drug reactions add to their economic burden.

Epilepsy is a chronic condition often requires long term treatment. There are currently more than 25 drugs in the market for the treatment of epilepsy, with similar efficacy but different tolerability profile. Due to the long duration of treatment, various adverse reactions are seen, which 
require change of medication and monitoring. ${ }^{3}$ The commonly prescribed drugs are phenytoin, carbamazepine and sodium valproate. Few newer antiepileptics like lamotrigine, leviteracetam, are also being prescribed. The neurological adverse effects include sedation, dizziness, coordination disturbances, tremor, fatigue, mood alterations, cognitive deficits and behavioural changes. The idiosyncratic reactions may manifest as simple morbilliform rashes as well as potentially fatal reactions such as Stevens-Johnson syndrome, toxic epidermolysis and DRESS syndrome. ${ }^{4}$ Chronic effects include hirsutism, gingival hyperplasia, and weight gain. ADRs account for considerable mortality and morbidity besides having immense economic impact on patients, health-care providers and society.

This study aims at identifying the serious adverse drug reactions due to antiepileptic drugs, reported at the pharmacovigilance centre of a tertiary care centre. The study also shows the common ADRs with routinely prescribed antiepileptics.

\section{METHODS}

It is a retrospective, descriptive, observational, pharmacovigilance study. All the cases that have been reported to the PV centre of a tertiary care centre relating to antiepileptic drugs during 2016- 2017 have been screened.

The ADRs were categorised to mild, moderate and severe based on modified Hartwig and Siegel scale of severity. ${ }^{5}$ According to modified Hartwig and Siegel scale of severity assessment, severe ADRs are potentially life threatening, causing permanent damage or those requiring intensive medical treatment and which either directly or indirectly led to the death of the patient.

The causal relationship was assessed according to WHO UMC causality assessment system into certain, probable, possible, unlikely, conditional and unassessable based on the association of ADR to the drug. ${ }^{6}$ Preventability of severe reactions was determined by Schumock and Thornton scale of preventability of ADR. ${ }^{7}$ They categorise the ADR into definitely preventable, probably preventable and not preventable. Descriptive statistics were used for analysis.

\section{RESULTS}

A total of 120 ADRs of antiepileptic drugs that were prescribed in the tertiary care centre were reported. They were screened and the following data was analysed.

\section{Demographic details}

Out of the total of 120 ADR reported, 64 belonged to male population and 56 to the female population. Higher incidence of ADR is observed in the age group of 16 to 35 years as shown in Table 1.
Table 1: Age wise distribution of ADRs.

\begin{tabular}{|l|l|}
\hline Age group & No. of ADRs \\
\hline $5-15$ & 7 \\
\hline $16-25$ & 49 \\
\hline $26-35$ & 30 \\
\hline $36-45$ & 22 \\
\hline $46-55$ & 12 \\
\hline
\end{tabular}

\section{Classification of ADR according to WHO-ART system organ classes.}

According to WHO-ART there are 32 organ system classes out of which 4 classes were found in the present study as shown in Table $2 .^{8}$

Table 2: WHO-ART organ system classification of ADRs.

\begin{tabular}{|c|c|c|c|}
\hline No. & $\begin{array}{l}\text { WHO- } \\
\text { Code }\end{array}$ & System organ classes & $\begin{array}{l}\text { No. of } \\
\text { ADR }\end{array}$ \\
\hline \multirow[t]{4}{*}{1} & 0410 & Central and pns disorder & 20 \\
\hline & & Ataxia & 13 \\
\hline & & Giddiness & 5 \\
\hline & & Drowsiness & 2 \\
\hline \multirow[t]{8}{*}{2} & 0100 & $\begin{array}{l}\text { Skin and appendages } \\
\text { disorder }\end{array}$ & 94 \\
\hline & & Rashes & 64 \\
\hline & & DRESS syndrome & 1 \\
\hline & & Erythroderma & 5 \\
\hline & & Steven- Johnson syndrome & 12 \\
\hline & & Toxic epidermal necrolysis & 5 \\
\hline & & Fixed drug eruption & 6 \\
\hline & & Lichenoid eruption & 2 \\
\hline \multirow[t]{3}{*}{3} & 1810 & $\begin{array}{l}\text { Body as a whole generalise } \\
\text { disorder }\end{array}$ & 3 \\
\hline & & Gingival hyperplasia & 2 \\
\hline & & ECG abnormality & 1 \\
\hline \multirow[t]{2}{*}{4} & 0600 & GIT disorders & 2 \\
\hline & & Acute pancreatitis & 2 \\
\hline
\end{tabular}

\section{Severity of ADRs}

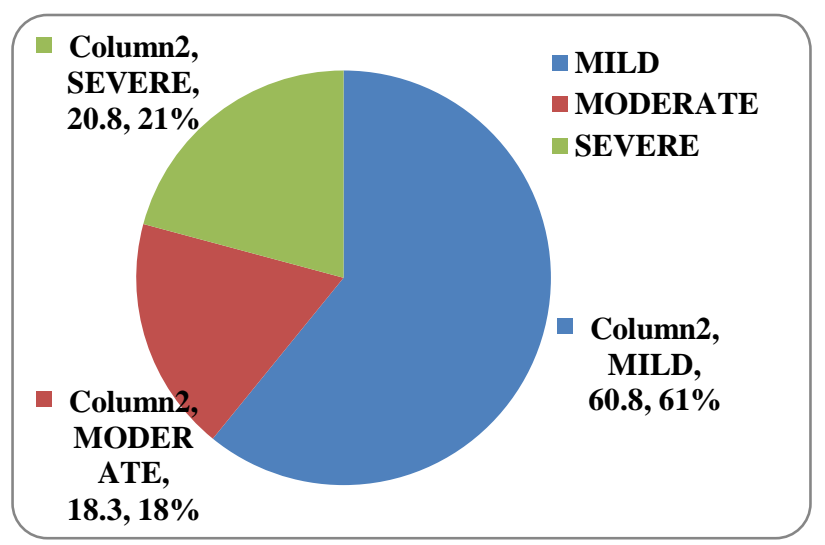

Figure 1: Severity of ADRs. 
The ADRs were categorised according to the modified Hartwig and Seigel scale. $60.8 \%$ were mild cases, $18.5 \%$ were moderate cases and $20.8 \%$ were severe cases as shown in Figure 1.

\section{Types of serious ADRs with probable drugs}

All the severe ADRs received along with the probable drugs causing them are enlisted below in Table 3 .

Table 3: Types of serious ADRs with probable drugs.

\begin{tabular}{|llll|}
\hline No & ADR & Drugs & Total \\
\hline 1 & $\begin{array}{l}\text { Steven-Johnson } \\
\text { syndrome }\end{array}$ & $\begin{array}{l}\text { Carbamazepine(6) } \\
\text { Phenytoin (6) }\end{array}$ & 12 \\
\hline 2 & $\begin{array}{l}\text { Toxic epidermal } \\
\text { necrolysis }\end{array}$ & $\begin{array}{l}\text { Phenytoin (3) } \\
\text { Carbamazepine (1) } \\
\text { Phenobarbitone(1) }\end{array}$ & 5 \\
\hline 3 & Erythroderma & $\begin{array}{l}\text { Phenytoin (3) } \\
\text { Carbamazepine (1) } \\
\text { Leviteraetam(1) }\end{array}$ & 5 \\
\hline 4 & $\begin{array}{l}\text { DRESS } \\
\text { syndrome }\end{array}$ & Phenytoin (1) & 1 \\
\hline 5 & Acute pancreatitis & Valproate (2) & 2 \\
\hline
\end{tabular}

\section{Probable drugs causing severe ADRS}

The probable drugs causing severe ADRs are enlisted in Table 4.

Table 4: Probable AED causing severe ADRs.

\begin{tabular}{|llll|}
\hline No. & Antiepileptic drug & No. of ADR & $\%$ \\
\hline 1 & Phenytoin & 13 & 52 \\
\hline 2 & Carbamazepine & 8 & 32 \\
\hline 3 & Phenobarbitone & 1 & 4 \\
\hline 4 & Leviteracetam & 1 & 4 \\
\hline 5 & Valproate & 2 & 8 \\
\hline
\end{tabular}

\section{Preventability of severe ADRs}

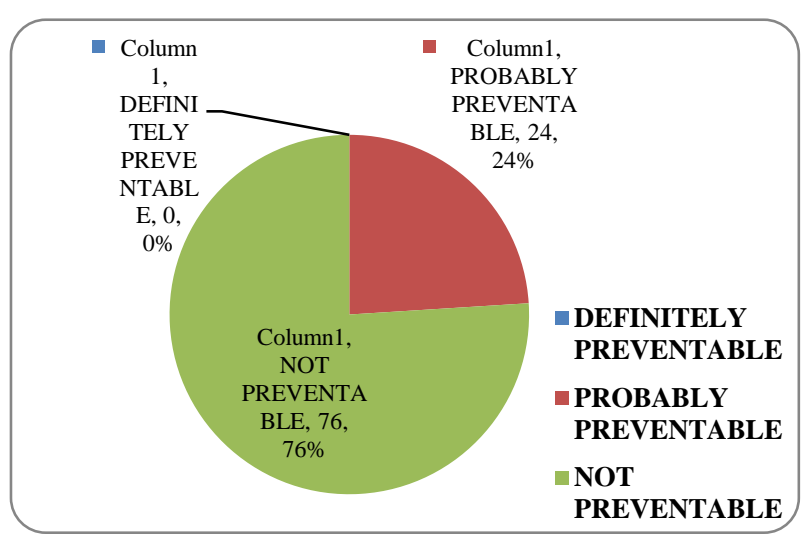

Figure 2: Preventability of severe ADRs.

According to the modified Schumock and Thornton criteria of ADR preventability, none of the ADR were definitely preventable, $24 \%$ were probably preventable and $76 \%$ were not preventable as shown in Figure 2.

\section{DISCUSSION}

This is a pharmacovigilance study of the adverse drug reactions reported at the pharmacovigilance centre of a tertiary hospital. A total of 120 ADRs of prescribed antiepileptic drugs were analysed. The majority of the ADRs belonged to the age group of 16-35 years. It is likely that this age group is attending hospital more frequently for epilepsy drug therapy as well as visiting for subsequent follow ups.

Most of the ADRs belonged to skin and appendages which ranged from mild rashes to severe Steven-Johnson syndrome. The ADRs include rashes, fixed drug eruptions, lichenoid eruption, Erythroderma, Toxic epidermal necrolysis, Steven -Johnson syndrome and DRESS syndrome.

The severity of ADRs were assessed by the modified Hartwig and Seigel scale, according to which 20.8\% ADRs were severe which include 12 cases of Steven- Johnson syndrome, 5 cases of Toxic epidermal necrolysis, 5 cases of erythroderma, 2 cases of acute pancreatitis, and 1 case of DRESS syndrome. WHO-Uppsala scale of causality assessment was used and all the probable drugs causing the ADR were identified as rechallenge of drug was avoided on the basis of ethical grounds, to ensure patient safety. Probable drugs implicated in causing the serious ADRs were phenytoin, carbamazepine, phenobarbitone, leviteracetam and sodium valproate. Modified Schumock and Thornton scale was used to assess the preventability of the serious ADRs, according to which $24 \%$ were probably preventable and $76 \%$ were not preventable. Carbamazepine induced Steven-Johnson syndrome is associated with high risk of development in individuals with HLA-B*1502 allele. US-FDA has also issued a labelling change for carbamazepine regarding this association. ${ }^{9}$ Monitoring of blood counts is essential during carbamazepine therapy, as identification of Agranulocytosis can result in reversal of blood counts, which might prevent the onset of serious infections. ${ }^{10}$

In the study conducted by Sasidharanpillai et al. It was found that, phenytoin was the most common drug involved, followed by carbamazepine for causing SJS. ${ }^{11}$ In this study there is equality of number of SJS caused by phenytoin and carbamazepine. The mortality rate of SJS varies, with a recent study showing a rate as high as $16.39 \%$ in the Indian population. ${ }^{12}$

Phenytoin is the most common and cheap AED used, which is associated maximum serious ADRs of $52 \%$ amongst the prescribed AED. Structured pharmacovigilance and therapeutic drug monitoring can be employed for drugs with narrow therapeutic index like phenytoin to manage the doses and prevent toxicity and ADRs. 


\section{CONCLUSION}

Antiepileptic drugs are associated with many ADRs, pharmacovigilance practice is essential for their detection, assessment and prevention. Serious ADRs causes' mortality, morbidity, increases the economic burden and loss of productive time of the patient and the family. Mortality due to the disease is acceptable but due to ADR is unacceptable, hence pharmacovigilance should be promoted at all levels nationally and globally to ensure patient safety and well being by sensitizing and encouraging the health care providers to report ADRs. Furthermore prospective studies should be done to understand the gravity of the ADR burden on health sytem. Establishment of antiepileptic drug ADR database can be a worthy long-term goal in the Indian context.

\section{ACKNOWLEDGEMENTS}

Authors would like to thank the Head of the department of Pharmacology of Gandhi medical college for her support and pharmacovigilance technical staff who were helpful in collecting the ADRs.

Funding: No funding sources

Conflict of interest: None declared

Ethical approval: The study was approved by the Institutional Ethics Committee

\section{REFERENCES}

1. WHO epilepsy fact sheet- updated feb 2018. Available at: $\quad$ www.int/mediacentre/factsheets/fs999/en/. Accessed in feb 2018

2. Nandanava SS, Sanjib S, Parthasarthy S. Epilepsy: Indian perspective. Ann Indian ACAD Neurol. 2014 March;17(1):S3-S11.

3. Keerthy J, Kavitha P, Sambathkumar R. A study on the Adverse Drug Reactions induced by antiepileptic drugs in the epileptic patients. Journal of applied Pharmaceutical Sciences. May 2016;6(05):119-23.

4. Perucca E. Adverse effects of antiepileptic drugs. Focus Farmacovigilanza. 2014;80(1):1.
5. Hartwig SC, Siegel J, Schneider PJ. Preventability and severity assessment in reporting adverse drug reactions. Am J Hosp Pharm. 1992;49:2229-32.

6. The use of the WHO- UMC system for standardised case causality assessment. WHO uppsala monitoring centre. Available at: http://www.whoumc.org/media/2786/standardised-case-causalityassessment pdf. Accessed in Feb 2018.

7. Schumock GT, Thornton JP. Focusing on the Preventability of Adverse Drug Reactions. Hosp. Pharm. 1992;27:538.

8. International Monitoring of Adverse Reactions to Drugs. WHO Adverse Reaction Terminology. Uppsala, Sweden: Uppsala Monitoring Centre; 2007.

9. Ferrell BB, Mc Leod HL. Carbamaazepine, HLAB*1502 and risks of Steven-Johnson syndrome and Toxic epidermal necrolysis: USFDA recommendations. Pharmacogenomics. 2008;9(10):15436-46.

10. Avinash A, Amberkar VM, Kunder SK, Madhyastha S, Meenakumari K. Carbamazepine-induced Lifethreatening Stevens-Johnson Syndrome and Agranulocytosis: The Maiden Case. Journal of clinical and diagnostic research: JCDR. 2016 Dec;10(12):FD01.

11. Sasidharanpillai S, Riyaz N, Khader A, Rajan U, Binitha MP, Sureshan DN. Severe cutaneous adverse drug reactions: A clinico epidemiological study. Indian J Dermatol. 2015;60(1):102.

12. Patel TK, Thakkar SH, Sharma DC. Cutaneous adverse drug reactions in Indian population: A systematic review. Indian Dermatol Online J. 2014;5(2):S76-86.

Cite this article as: Khan SZ, Ali MA, Subhani G, Ushasree T. A study of serious adverse drug reactions with antiepileptic drugs: a pharmacovigilance study. Int J Basic Clin Pharmacol 2018;7:922-5. 